\title{
Influence of Different Staining Beverages on Color Stability, Surface Roughness and Microhardness of Silorane and Methacrylate-based Composite Resins
}

\author{
${ }^{1}$ Emel Karaman, ${ }^{2}$ Duygu Tuncer, ${ }^{3}$ Esra Firat, ${ }^{4}$ Oguz Suleyman Ozdemir, ${ }^{5}$ Sevilay Karahan
}

\begin{abstract}
Aim: To investigate the influence of different staining beverages on color stability, surface roughness and microhardness of silorane and methacrylate-based composite resins.

Materials and methods: Three different composite resins (Filtek Silorane, Filtek P60, Filtek Supreme XT) were tested. Thirty cylindrical specimens $(10 \times 2 \mathrm{~mm})$ per material were prepared and polished with a series of aluminum-oxide polishing disks. Each group was then randomly subdivided into three groups according to the test beverages: distilled water (control), cola and coffee. The samples were immersed into different beverages for 15 days. Color, surface roughness and microhardness values were measured by a spectrophotometer, prophylometer and Vickers hardness device respectively, at baseline and after 15 days. The data were subjected to statistical analysis.
\end{abstract}

Results: Immersion in coffee resulted in a significant discoloration for all the composites tested, although the color change was lower in Filtek Silorane than that of MBCs $(p<0.05)$. All the composites tested showed similar surface roughness changes after immersion in different beverages $(p>0.05)$. Besides coffee caused more roughness change than others. Immersion in coffee caused highest microhardness change in Filtek Supreme XT $(p<0.05)$.

Conclusion: Cola and coffee altered, to some degree, the color, surface roughness and/or microhardness of the tested resin composites, depending on the characteristics of the materials.

Keywords: Color stability, Surface roughness, Microhardness, Composite resin, Different beverage.

\footnotetext{
${ }^{1-3,5}$ Assistant Professor, ${ }^{4}$ Doctor

${ }^{1}$ Department of Restorative Dentistry, Ondokuz Mayis University, Faculty of Dentistry, Turkey

${ }^{2}$ Department of Restorative Dentistry, Bașkent University Faculty of Dentistry, Turkey

${ }^{3}$ Department of Restorative Dentistry, Hacettepe University Faculty of Dentistry, Turkey

${ }^{4}$ Department of Prosthodontics, Ondokuz Mayis University Faculty of Dentistry, Turkey

${ }^{5}$ Department of Biostatistics, Hacettepe University, School of Medicine, Turkey
}

Corresponding Author: Emel Karaman, Assistant Professor Department of Restorative Dentistry, Ondokuz Mayis University Faculty of Dentistry, Turkey, e-mail: dtemelkaraman@gmail.com
How to cite this article: Karaman E, Tuncer D, Firat E, Ozdemir OS, Karahan S. Influence of Different Staining Beverages on Color Stability, Surface Roughness and Microhardness of Silorane and Methacrylate-based Composite Resins. J Contemp Dent Pract 2014;15(3):319-325.

Source of support: Nil

Conflict of interest: None declared

\section{INTRODUCTION}

Composite resins are defined as the choice material for the direct restoration of both anterior and posterior teeth because of their physical and mechanical properties, excellent initial esthetics, moderate cost compaired to ceramics and adhesion to tooth structure.

Discoloration of composite resins is an unacceptable situation for patients and may lead to additional expense for replacement. One of the most common reasons for this problem is surface or subsurface changes which led to slight penetration and reaction of staining agents on the superficial layer of composite resins. ${ }^{1}$ Since, the diet contain a variety of colored food and drinks, they can alter the color of the resin composites through absorption and/or adsorption of colorants during the long period of exposure. ${ }^{2,3}$ Color alteration with different beverages, such as coffee, tea and cola drinks, have been reported by many studies. ${ }^{4,5}$ Some of these beverages can also reduce the microhardness ${ }^{6}$ and roughness ${ }^{7}$ of composite surface and cause more staining.

Resistance to dissolution or disintegration is one of the most important properties that determines the durability of restorative materials. ${ }^{8}$ As the wear resistance of dental materials has a significant impact on the clinical performances of restorations, hardness tests are used to predict the wear resistance of dental materials. ${ }^{9}$ In the same vein, since a material's surface roughness properties have an influence on its esthetics, friction, wear, optical properties and accumulation of dental plaque, ${ }^{10,11}$ its surface roughness measurement is also performed.

The search for an ideal restorative material with good esthetic and mechanical properties have led to the development of a number of new restorative materials. Several types of composites are available for esthetic restorations, differ from each other according to the type of resin matrix, size, 
type and amount of filler particles. Moreover, the matrix structure and the inorganic fillers of composite resin as well as the features of inorganic fillers have a direct effect on surface smoothness of composite resin restorations and on the staining ability. ${ }^{12}$

Recently, a novel cationic-posterior composite known as silorane has been introduced and suggested as alternative to methacrylates as matrix resin component for dental composites because of it's physical properties. ${ }^{13}$ The siloranebased composite (SBC) has a different resin chemistry from the commonly used methacrylate-based composites (MBCs). The silorane is composed of two main components. The first one is siloxane, which is a hydrophobic part giving the stability of the material. The second part is oxirane, which is responsible for cationic polymerization reaction. ${ }^{14}$ Buchalla et $\mathrm{al}^{12}$ have reported that hydrophilic matrices are more susceptible to water absorption, dye penetration and staining than hydrophobic ones. Thus, the purpose of this study was to assess the color stability, surface roughness and microhardness of three types of composite resins, one silorane-based and two methacrylate-based, exposed to cola and coffee.

The tested hypotheses were that there would be no difference in color stability, surface roughness and microhardness of SBC and MBCs after immersion in different staining beverages and different staining beverages would not effect the amount of color stability, surface roughness and microhardness change of tested composite resins.

\section{MATERIALS AND METHODS}

Three different composite resins (Filtek Silorane (siloranebased composite), Filtek P60 (microhybrid methacrylate-based composite), Filtek Supreme XT (nanohybrid methacrylatebased composite) from the same company (3M ESPE, St Paul, MN, USA) all in A3 shade were tested. The composite resins used in the current study are listed in Table 1.

\section{Specimen Preparation}

Thirty cylindrical specimens were prepared for each of three composite resins in teflon ring molds $(10 \mathrm{~mm}$ in diameter and $2 \mathrm{~mm}$ height). A polyester strip was placed on a glass slab (Dentsply, Petropolis, Rio de Janeiro, Brazil) and teflon matrix. After filling the mold to excess, the material surface was covered with another polyester strip and a glass slide, and compressed with a device (500 gm) for 20 seconds to accommode the resin better and remove the excess material. All the resin composite specimens were light cured with an LED device (SDI, Radii Plus) according to the manufacturers' instructions. The polymerization of the specimens was carried out at four quadrants on each top and bottom sides against the strip and glass plate, and then for another similar amount of irradiation but without the glass plates. The curing tip was positioned perpendicular to specimen's surface. The power output density used was $1000 \mathrm{~mW} / \mathrm{cm}^{2}$, frequently monitored by means of a radiometer. In order to replicate the oral conditions following polymerization, the specimens were stored in distilled water for 24 hours before finishing and polishing. ${ }^{15}$ Then, all specimens were finished with a series of aluminum oxide polishing disks (Sof-Lex, 3M ESPE, Dental Products) in a sequence of decreasing abrasiveness with intermittent movements, under constant water cooling. Polishing procedures were kept to a minimum time, 10 seconds for each step, to avoid micro-crack formation. ${ }^{16}$ Subsequently, baseline color, surface roughness and microhardness values were masured.

\section{Color Measurements}

The color of the specimens was measured with a VITA Easyshade (Vident, Brea, CA, USA) spectrophotometer, using the CIELAB scale, and the effects of discoloration were expressed in $\Delta \mathrm{E}^{*}$ units and calculated from the $\Delta \mathrm{L}^{*}$, $\Delta \mathrm{a}^{*}$, and $\Delta \mathrm{b}^{*}$ averages using the following equation:

$$
\Delta \mathrm{E}^{*}=\left[\left(\Delta \mathrm{L}_{0}^{*}-\Delta \mathrm{L}_{1}^{*}\right)^{2}+\left(\Delta \mathrm{a}_{0}^{*}-\Delta \mathrm{a}_{1}^{*}\right)^{2}+\left(\Delta \mathrm{b}_{0}^{*}-\Delta \mathrm{b}_{1}^{*}\right)^{2}\right]^{1 / 2} .
$$

The device was calibrated before the measurement of each specimen.

\section{Surface Roughness Measurements}

The surface roughness was measured by using a contact profilometer (Surfcorder SE 1700, Kosaka Corp, Tokyo, Japan) equipped with a $5 \mathrm{~mm}$ radius diamond-tipped stylus that was attached to a pickup head. The stylus traversed the

Table 1: Composite resins used in the study

\begin{tabular}{|c|c|c|c|c|c|}
\hline Material (batch no.) & Shade & Type & Composition & Filler (vol \%) & Manufacturer \\
\hline $\begin{array}{l}\text { Filtek Silorane } \\
\text { (N105399) }\end{array}$ & A3 & $\begin{array}{l}\text { Microhybrid } \\
\text { composite }\end{array}$ & $\begin{array}{l}\text { Matrix: Silorane (oxirane and siloxane) } \\
\text { Filler: Epoxy functional silane-treated } \mathrm{SiO}_{2} \\
\text { and ytterbium fluoride }(0.1-2 \mu \mathrm{m})\end{array}$ & 55 & $\begin{array}{l}\text { 3M ESPE, St Paul, } \\
\text { MN, USA }\end{array}$ \\
\hline Filtek P60 (8 NW) & A3 & $\begin{array}{l}\text { Microhybrid } \\
\text { composite }\end{array}$ & $\begin{array}{l}\text { Matrix: Bis-GMA, UDMA, Bis-EMA } \\
\text { Filler: zirconia/silica }(0.01-3.5 \mu \mathrm{m})\end{array}$ & 61 & $\begin{array}{l}\text { 3M ESPE, St Paul, } \\
\text { MN, USA }\end{array}$ \\
\hline $\begin{array}{l}\text { Filtek Supreme XT } \\
\text { (N106934) }\end{array}$ & A3 & $\begin{array}{l}\text { Nanofilled } \\
\text { composite }\end{array}$ & $\begin{array}{l}\text { Matrix: Bis-GMA, UDMA, Bis-EMA, } \\
\text { TEGDMA } \\
\text { Filler: zirconia/silica }(0.6-1.4 \mu \mathrm{m})\end{array}$ & 59.5 & $\begin{array}{l}\text { 3M ESPE, St Paul, } \\
\text { MN, USA }\end{array}$ \\
\hline
\end{tabular}

Bis-GMA: Bisphenol A glycol dimethacrylate; UDMA: Urethane dimethacrylate; Bis-EMA: Ethoxylated bisphenol A glycol dimethacrylate; TEGDMA: Triethylene glycol dimethacrylate 
surface of the specimen at a constant speed of $0.5 \mathrm{~mm} / \mathrm{second}$ with a force of $4 \mathrm{mN}$ and automatic return. Each specimen was traced in four parallel locations near the center across the finished and/or polished surface with an evaluation length of $4 \mathrm{~mm}$. Leveling of all parts of the apparatus was achieved by adjusting the pickup head knob. A calibration block was used periodically to check the performance of the profilometer.

\section{Vickers Surface Microhardness Measurements}

Vickers surface microhardness (HMV 2000, Shimadzu, Kyoto, Japan) was determined by performing three indentations with $50 \mathrm{gm}$ load for 15 seconds (100 $\mu \mathrm{m}$ of distance).

\section{Staining Protocol}

To evaluate the changes in different beverages, 30 specimens of each group were subdivided into three subgroups of 10 specimens as follows:

- Subgroup A (control): Specimens were stored in 150 $\mathrm{ml}$ distilled water and the solution was changed daily. Distilled water was used as a control and to investigate intrinsic color changes in the restorative materials.

- Subgroup B: Specimens were stored in $37^{\circ} \mathrm{C}$ coffee (Nescafe, New Delhi, India). For preparation of coffee Solution, 2.8 gm of coffee was prepared (Precisa $1620 \mathrm{C}$ sensitive weight, Switzerland) and added to $150 \mathrm{ml}$ of boiling distilled water. The coffee was freshly prepared daily prior to each test period.

- Subgroup C: Specimens were stored in $37^{\circ} \mathrm{C}$ Cola carbonated soft drink (Coca-Cola ${ }^{\circledR}$, Refrescos Ipiranga, Ribeirão Preto, SP, Brazil). The lids of the containers were tightly closed to prevent escape of carbonic gas. In order to maintain an acceptable level of carbonic gas, a new bottle was used everyday.

All specimens were stored in light-proof containers at $37^{\circ} \mathrm{C}$ in an incubator (Nüve EN 120 Incubator, Ankara, Turkey). After 15 days of immersion in the solutions, the specimens were rinsed with distilled water for 5 minutes and blotted dry with absorbent paper before the final measurements. ${ }^{17}$ All baseline and final measurements were performed by the same operator. Three measurements were recorded for each specimen and the mean values for each group and variables were calculated. Color $(\Delta \mathrm{E})$, roughness
$(\Delta \mathrm{Ra})$ and microhardness $(\Delta \mathrm{V})$ changes which represent the difference between the initial and final measurements for each group were also calculated.

\section{STATISTICAL ANALYSIS}

Baseline color, surface roughness and microhardness values of groups were evaluated with Welch ANOVA test. KruskalWallis test was used to evaluate the effects of material type and beverage on color change. Multiple comparisons were evaluated with Mann-Whitney U test with Bonferroni correction. Two-way analysis of variance was used to evaluate the effects of material type and staining beverage on microhardness and surface roughness changes. Tukey HSD test was used for multiple comparisons. Pearson correlation regression analysis was carried out to evaluate the possible correlations between color, roughness and microhardness values. All statistical analyses were performed using a standard statistical software package (SPSS 15.0.1, Chicago, USA) at a significance level of $\mathrm{p}=0.05$.

\section{RESULTS}

The baseline means (standard deviations) of the composite resin groups and subgroups tested are shown in Table 2. There were significant differences among the different composite resins for color, surface roughness and microhardness at baseline $(\mathrm{p}<0.001)$. Filtek Silorane revealed the highest baseline L values, whereas Filtek Supreme XT exhibited the highest $\mathrm{a}$ and $\mathrm{b}$ values $(\mathrm{p}<0.001)$. The surface roughness values of Filtek Silorane was higher than Filtek Supreme XT and Filtek P60 at baseline $(\mathrm{p}<0.001)$. Filtek Silorane and Filtek Supreme XT exhibited the lowest and highest baseline microhardness values respectively, and they were both statistically different from Filtek P60 (p < 0.001). However, the comparisons of subgroups within each composite resin at baseline revealed no significant differences in terms of color, surface roughness and microhardness ( $p>0.05)$.

Table 3 shows the means (standard deviations) and statistically significant differences on color change in tested composite resins after immersion in different staining beverages. Coffee showed the highest color change which is followed by cola, whereas distilled water caused the least color change $(p<0.05)$. There was a significant difference

Table 2: Baseline means (standard deviations) for color, surface roughness and microhardness values of different composite resins

\begin{tabular}{llllll}
\hline $\begin{array}{l}\text { Composite resin groups } \\
(n=30)\end{array}$ & \multicolumn{3}{c}{ Color } & Roughness (Ra) & Microhardness (V) \\
\cline { 2 - 4 } & $\mathrm{L}$ & $\mathrm{a}$ & $b$ & & \\
\hline Filtek Silorane & $77.9(1.0)^{\mathrm{A}}$ & $1.9(0.2)^{\mathrm{A}}$ & $23.8(0.8)^{\mathrm{A}}$ & $0.13(0.03)^{\mathrm{A}}$ & $55.4(3.6)^{\mathrm{A}}$ \\
Filtek P60 & $73.6(0.6)^{\mathrm{B}}$ & $0.4(0.2)^{\mathrm{B}}$ & $19.0(0.7)^{\mathrm{B}}$ & $0.10(0.02)^{\mathrm{B}}$ & $82.7(4.0)^{\mathrm{B}}$ \\
Filtek Supreme XT & $76.9(0.6)^{\mathrm{C}}$ & $2.2(0.3)^{\mathrm{C}}$ & $29.7(0.8)^{\mathrm{C}}$ & $0.09(0.02)^{\mathrm{B}}$ & $90.6(4.1)^{\mathrm{C}}$ \\
p-value & $<0.001$ & $<0.001$ & $<0.001$ & $<0.001$ & $<0.001$ \\
\hline
\end{tabular}

Different uppercase letters in columns indicate statistically significant difference among different composite resin groups 
among the tested composite resins when immersed in cola and coffee $(\mathrm{p}<0.05)$, while immersion in distilled water did not create a significant color change among groups $(p>0.05)$. Filtek Silorane specimens showed the least color changes after 15 days immersion in all three test beverages, which were significantly lower than that of Filtek Supreme XT and Filtek P60 $(\mathrm{p}<0.05)$. Filtek Silorane and Filtek Supreme XT exhibited higher color change after immersion in coffee in comparison with cola and distilled water ( $\mathrm{p}<$ 0.05 ). The differences among the color change values for all beverages used were statistically significant for Filtek P60 (coffee $>$ cola $>$ distilled water $)(\mathrm{p}<0.05)$.

The means (standard deviations) and statistically significant differences on surface roughness change of composite resins in different staining beverages have been shown in Table 4 . There was no statistically significant difference among the tested composite resins when immersed in different beverages for 15 days $(p>0.05)$. The interactions of materials and staining beverages were significantly different within all groups $(p<0.05)$. In Filtek Silorane and Filtek Supreme XT, immersion in coffee caused more surface roughness change than distilled water and cola $(\mathrm{p}<$ 0.05 ), while the surface roughness change in Filtek P60 was similar with cola and coffee $(p>0.05)$, which were higher than distilled water $(\mathrm{p}<0.05)$.

In Table 5, means (standard deviations) and statistically significant differences on microhardness change for each composite resins are presented. There were no statistically significant differences among the tested composite resins when immersed in distilled water and cola $(\mathrm{p}>0.05)$. However, Filtek Supreme XT exhibited significantly higher microhardness change when immersed in coffee $(p<0.001)$. The interactions of materials and staining beverages were not significantly different in Filtek Silorane and Filtek P60 subgroups $(p>0.05)$, but coffee caused a significantly higher microhardness change than cola and distilled in Filtek Supreme XT $(\mathrm{p}<0.05)$.

\section{DISCUSSION}

Three commercially available composite resins from the same company were evaluated in this study. Depending on this study's findings, the SBC had different properties at baseline when compaired to MBCs. Different chemical characteristics, inorganic filler content, filler size and polymerization process of these composite resins may be responsible for the differences on baseline color, surface roughness and microhardness values. ${ }^{18,19}$ Because of the baseline heterogeneities among the materials, affects of the test beverages on composite resins were evaluated, by calculating the color, surface roughness and microhardness value changes between baseline and 15 days of immersion, to eliminate any possible artifact that may influence the results of the study.

Table 3: Means (standard deviations) for color change of composite resins

\begin{tabular}{lcccc}
\hline Composite resin groups & Distilled water & Cola & Coffee & \multirow{2}{*}{$p$-value } \\
\cline { 2 - 4 }$(n=30)$ & $\Delta E$ & $\Delta E$ & $\Delta E$ & 0.002 \\
\hline Filtek Silorane & $1.01(0.28)^{\mathrm{a}, \mathrm{A}}$ & $1.07(0.47)^{\mathrm{a}, \mathrm{A}}$ & $2.76(0.78)^{\mathrm{b}, \mathrm{A}}$ & 0.001 \\
Filtek P60 & $1.50(0.97)^{\mathrm{a}, \mathrm{A}}$ & $3.24(1.17)^{\mathrm{b}, \mathrm{B}}$ & $9.11(1.40)^{\mathrm{c}, \mathrm{B}}$ & 0.001 \\
Filtek Supreme XT & $1.58(0.57)^{\mathrm{a}, \mathrm{A}}$ & $2.33(0.77)^{\mathrm{a}, \mathrm{B}}$ & $8.41(1.00)^{\mathrm{b}, \mathrm{B}}$ & \\
p-value & 0.117 & 0.002 & 0.001 & \\
\hline
\end{tabular}

Different lowercase letters in rows and uppercase letters in columns indicate statistically significant difference

Table 4: Means (standard deviations) for surface roughness change of composite resins

\begin{tabular}{lcccc}
\hline Composite resin groups & Distilled water & Cola & Coffee & \multirow{2}{*}{$p$-value } \\
\cline { 2 - 3 }$(n=30)$ & $\Delta R a$ & $\Delta R a$ & $\Delta R a$ & 0.030 \\
\hline Filtek Silorane & $-0.02(0.02)^{\mathrm{a}, \mathrm{A}}$ & $0.01(0.04)^{\mathrm{a}, \mathrm{A}}$ & $0.02(0.04)^{\mathrm{b}, \mathrm{A}}$ & 0.003 \\
Filtek P60 & $-0.03(0.02)^{\mathrm{a}, \mathrm{A}}$ & $0.01(0.04)^{\mathrm{b}, \mathrm{A}}$ & $0.02(0.03)^{\mathrm{b}, \mathrm{A}}$ & 0.030 \\
Filtek Supreme XT & $-0.01(0.02)^{\mathrm{a}, \mathrm{A}}$ & $-0.006(0.02)^{\mathrm{a}, \mathrm{A}}$ & $0.03(0.05)^{\mathrm{b}, \mathrm{A}}$ & \\
p-value & 0.344 & 0.468 & 0.736 & \\
\hline
\end{tabular}

Different lowercase letters in rows and uppercase letters in columns indicate statistically significant difference

Table 5: Means (standard deviations) for microhardness change of composite resins

\begin{tabular}{lcccc}
\hline Composite resin & Distilled water & Cola & Coffee & \multirow{2}{*}{$p$-value } \\
\cline { 2 - 4 } groups $(n=30)$ & $\Delta V$ & $\Delta V$ & $\Delta V$ & 0.144 \\
\hline Filtek Silorane & $-2.5(5.6)^{\mathrm{a}, \mathrm{A}}$ & $-8.8(4.1)^{\mathrm{a}, \mathrm{A}}$ & $-5.5(8.2)^{\mathrm{a}, \mathrm{A}}$ & 0.135 \\
Filtek P60 & $-2.1(8.5)^{\mathrm{a}, \mathrm{A}}$ & $-4.9(2.6)^{\mathrm{a}, \mathrm{A}}$ & $-8.5(5.9)^{\mathrm{a}, \mathrm{A}}$ & 0.001 \\
Filtek Supreme XT & $-4.9(5.2)^{\mathrm{a}, \mathrm{A}}$ & $-12.6(12.6)^{\mathrm{a}, \mathrm{A}}$ & $-24.7(5.9)^{\mathrm{b}, \mathrm{B}}$ & \\
p-value & 0.637 & 0.056 & 0.001 & \\
\hline
\end{tabular}

Different lowercase letters in rows and uppercase letters in columns indicate statistically significant difference 
The staining beverages used in this study induced varying degrees of discoloration in the tested composite resins. Immersion of the specimens in distilled water did not alter the color of the composite to a considerable extent, which is in agreement with other investigations. ${ }^{20-22}$ As distilled water has no pigments, the slight color alterations reported in this study might be attributed to some water sorption of the organic matrix. ${ }^{23}$ Coffee has a strong staining effect on resin composites and natural tooth structures. ${ }^{24,25}$ In the present study coffee caused the most severe discoloration among all the tested beverages for all tested composite resins. The absorption and adsorption of polar yellow colorants in coffee into the organic phase of composite resins may be responsible of this severe discoloration. ${ }^{26}$ Although cola, might be expected to damage the surface integrity as a result of its lower $\mathrm{pH}$ and cause more discoloration than other tested beverages; it did not cause discoloration as much as coffee. This result may be reletad to the lack of yellow colorants in it's content. In addition, the presence of phosphate ions in cola may suppress the dissolution since these ions have been shown to reduce the dissolution rate of calcium phosphate from the tooth. ${ }^{27}$

The findings of the current study for the evaluation of staining capacity of different beverages are in accordance with the previous studies, which have reported that coffee caused more discoloration than cola. ${ }^{2,17,18}$

Color change evaluation results of this study according to different composites showed that the least stainability was observed in SBC, in all staining solutions tested, which is in contrast with Pires-de-Souza et $\mathrm{al}^{29}$ who have reported that $\mathrm{SBC}$ showed highest discoloration. On the contrary, supporting our findings, Palin et a ${ }^{30}$ have reported that SBC was more resistant against staining by the colorant solutions than MBCs. It has been reported that SBC exhibited increased hydrophobicity due to the presence of the siloxane species. ${ }^{31}$ As Reis et $\mathrm{al}^{32}$ have shown that hydrophobic materials have a lower degree of water sorption and relatively lower discoloration value than hydrophilic ones, this finding can be explained by the lower water sorption of SBC.

Studies have suggested that color alteration in restorative materials should be $\Delta \mathrm{E}>1$ to be visually perceptible, and that $\Delta \mathrm{E}>3.3$ would be considered an undesired value for clinical success of the restoration. ${ }^{20,24}$ The discoloration caused by coffee in all MBCs tested were higher than 3.3, and clinically unacceptable. Although it has been previously reported that Filtek Supreme was more susceptible to staining than Filtek P60, ${ }^{28,33}$ since it included TEGDMA; they exhibited similar discoloration levels in all tested beverages in the present study.

Baseline surface roughness measurements showed that MBCs had smoother surface than SBC after polishing while no significant differences in surface roughness were found among the composite resins when immersed in distilled water, cola and coffee. The average roughness values of tested composite resins ranged from 0.13 to 0.09 and these values were below the critical thereshold value of $0.2 \mu \mathrm{m}$, which allows plaque accumulation. ${ }^{16}$

The resin matrix and filler particles have different levels of hardness that cause variations in removal efficiency during polishing, and that these variations can lead to differences in surface roughness. ${ }^{34,35}$ The roughness of a composite resin is releated not only to the type of it but also to the employed finishing and polishing technique. In this study, all specimens were polished with a series of aluminum oxide polishing disks (Sof-Lex), since this technique have been reported to be the best way to generate low roughness in resin surfaces. ${ }^{36-38}$ Therefore, the baseline variabilites observed on the surface roughness of different materials might be attributed to the varied polishing responses of the composite materials tested.

The roughness change evaluations of tested composite resins after immersion of different baverages revealed that the surface roughness increased upon immersion in coffee. This result does not corroborate the study of Kitchens and Owens ${ }^{39}$ who did not found surface roughness increase of enamel when immersed in coffee. However, our findings are consistent with the results reported by Da Silva et $\mathrm{al}^{40}$ who detected significant degradation of the resin matrix with immersion in coffee.

Composite degradation is the result of complex reactions among different factors. ${ }^{13}$ Water is directly related to the composite organic matrix deterioration as it's absorption results in a widespread process within the composite resin matrix that causes its degradation and results in lower physical and mechanical properties, ${ }^{14,41}$ above all related to resin hardness as well as roughness. ${ }^{1}$ Previous studies have widely reported that water had the effect of reducing the surface hardness of methacrylate-based composite resins. ${ }^{42,43}$ In the present study distilled water showed surface hardness reduction in all of the composite resins tested after 15 days of immersion period, but they did not differ significantly from each other in accordance with previous studies' findings. ${ }^{6,44}$

As regards microhardness alterations, it was observed that acid substances can cause a reduction in the surface microhardness of composites by softening the bisphenol A glycidyl methacrylate-based polymers present in the organic matrix. ${ }^{45-47}$ In agreement with this theory, Villalta et $\mathrm{al}^{21}$ stated that low $\mathrm{pH}$ may indeed affect the surface integrity of composite resins and, for this reason, it could also promote an increase in the susceptibility to staining. In this study despite the lowest $\mathrm{pH}$, cola did not change the surface microhardness as much as coffee in Filtek P60 and Filtek Supreme XT specimens. Coffee caused the highest surface microhardness 
change in these groups, while cola induced the highest surface microhardness change in Filtek Silorane specimens. In the light of these findings, microhardness alterations could not be exclusively associated with $\mathrm{pH}$. In accordance with these findings, Soares-Geraldo et $\mathrm{al}^{23}$ and Hamouda ${ }^{48}$ have also reported that $\mathrm{pH}$ of the beverages did not effect the hardness change of composite resins as expected. Further investigations may be benefical for identifying the other chemical and physical properties of these substances that may effect the change in microhardness of composite resins.

Filtek Silorane exhibited similar surface microhardness decrease after immersion in distilled water and cola with MBCs. The microhardness decrease of Filtek Silorane after immersion in coffee was similar with Filtek P60 and lower than Filtek Supreme XT. Filtek Supreme XT group showed the highest microhardness change among groups, in all tested staining beverages. TEGDMA content of Filtek Supreme XT could serve as a possible explanation for this finding. Calais and Söderholm ${ }^{49}$ have reported that increasing the TEGDMA content in the resin matrix led to an increase in water uptake since this monomer is more hydrophilic than Bis-GMA and UDMA. Furthermore, Filtek Silorane and P60 have been marketed as posterior composites and posterior composites have been designed to have higher wear resistance than anterior ones as known.

The hypotheses tested in this study were rejected. Different staining solutions and different composite resins produced different levels of color, surface roughness and microhardness change after 15 days immersion.

\section{CONCLUSION}

Within the limitations of this in vitro study, the following conclusions can be made:

1. MBCs are more susceptible to staining than SBC.

2. Coffee has a significant influence on discoloration of both silorane and methacrylate-based composite resins.

3. Surface roughness and microhardness changes of composite resins in different staining solutions are material dependent.

\section{CLINICAL SIGNIFICANCE}

Silorane-based composites are more color stable than methacrylate-based composites in different staining solutions. More studies are needed to clarify silorane-based composites performance.

\section{REFERENCES}

1. Asmussen E, Hansen EK. Surface discoloration of restorative resins in relation to surface softening and oral hygiene. Scandinavian J Dent Res 1986 Apr;94(2):174-177.
2. Bagheri R, Burrow MF, Tyas M. Influence of food-simulating solutions and surface finish on susceptibility to staining of aesthetic restorative materials. J Dentist 2005 May;33(5):389-398.

3. Topcu FT, Sahinkesen G, Yamanel K, Erdemir U, Oktay EA, Ersahan S. Influence of different drinks on the colour stability of dental resin composites. European J Dentist 2009 Jan;3(1):50-56.

4. Yazici AR, Celik C, Dayangac B, Ozgunaltay G. The effect of curing units and staining solutions on the color stability of resin composites. Operat Dentist 2007 Nov-Dec;32(6):616-622.

5. Park JK, Kim TH, Ko CC, Garcia-Godoy F, Kim HI, Kwon YH. Effect of staining solutions on discoloration of resin nanocomposites. Am J Dentist 2010;23(1):39-42.

6. Yanikoglu N, Duymus ZY, Yilmaz B. Effects of different solutions on the surface hardness of composite resin materials. Dent Materials J 2009 May;28(3):344-351.

7. Badra VV, Faraoni JJ, Ramos RP, Palma-Dibb RG. Influence of different beverages on the microhardness and surface roughness of resin composites. Operat Dentist 2005 Mar-Apr;30(2):213-219.

8. Nomoto R, McCabe JF. A simple acid erosion test for dental water-based cements. Dent Materials 2001 Jan;17(1):53-59.

9. Anusavice KJ. Philips' science of dental materials, 11 th ed. WB Saunders, Philadelphia; 2003. p. 1-832.

10. Pedrini D, Candido MS, Rodrigues AL. Analysis of surface roughness of glass-ionomer cements and compomer. J Oral Rehabilitation 2003 July;30(7):714-719.

11. Paravina RD, Roeder L, Lu H, Vogel K, Powers JM. Effect of finishing and polishing procedures on surface roughness, gloss and color of resin-based composites. Am J Dentist 2004 Aug;17(4):262-266.

12. Buchalla W, Attin T, Hilgers RD, Hellwig E. The effect of water storage and light exposure on the color and translucency of a hybrid and a microfilled composite. J Prosthet Dent 2002 Mar;87(3):264-270.

13. Guggenberger R, Weinmann W. Exploring beyond methacrylates. Am J Dent 2000;13(Spec No):82D-84D.

14. Eick JD, Kotha SP, Chappelow CC, Kilway KV, Giese GJ, Glaros AG, Pinzino CS. Properties of silorane-based dental resins and composites containing a stress-reducing monomer. Dent Materials 2007 Aug;23(8):1011-1017.

15. Malhotra N, Shenoy RP, Acharya S, Shenoy R, Mayya S. Effect of three indigenous food stains on resin-based, microhybrid and nanocomposites. J Esthet Restorat Dent 2011 Aug;23(4):250-257.

16. Marghalani HY. Effect of finishing/polishing systems on the surface roughness of novel posterior composites. J Esthetic Restorative Dentist 2010 Apr;22(2):127-138.

17. Mundim FM, Garcia Lda F, Pires-de-Souza Fde C. Effect of staining solutions and repolishing on color stability of direct composites. J Appl Oral Sci 2010 May-Jun;18(3):249-254.

18. Buchgraber B, Kqiku L, Allmer N, Jakopic G, Stadtler P. Surface roughness of one nanofill and one silorane composite after polishing. Collegium Antropologicum $2011 \mathrm{Sep}$;35(3):879-883.

19. Kusgoz A, Ulker M, Yesilyurt C, Yoldas OH, Ozil M, Tanriver M. Silorane-based composite: depth of cure, surface hardness, degree of conversion, and cervical microleakage in Class II cavities. J Esthetic Restorative Dentist 2011 Oct;23(5):324-335.

20. Stober T, Gilde H, Lenz P. Color stability of highly filled composite resin materials for facings. Dent Materials 2001 Jan; 17(1): 87-94.

21. Villalta P, Lu H, Okte Z, Garcia-Godoy F, Powers JM. Effects of staining and bleaching on color change of dental composite resins. J Prosthet Dentist 2006 Feb;95(2):137-142. 
22. Catelan A, Briso AL, Sundfeld RH, Goiato MC, dos Santos PH. Color stability of sealed composite resin restorative materials after ultraviolet artificial aging and immersion in staining solutions. J Prosthet Dentist 2011 Apr;105(4):236-241.

23. Soares-Geraldo D, Scaramucci T, Steagall-W Jr, Braga SR, Sobral MA. Interaction between staining and degradation of a composite resin in contact with colored foods. Brazilian Oral Res 2011 Jul-Aug;25(4):369-375.

24. Um CM, Ruyter IE. Staining of resin-based veneering materials with coffee and tea. Quintessence Int 1991 May;22(5):377-386.

25. Chan KC, Hormati AA, Kerber PE. Staining calcified dental tissues with food. J Prosthet Dentist 1981 Aug;46(2):175-178.

26. Lu H, Roeder LB, Powers JM. Effect of polishing systems on the surface roughness of microhybrid composites. J Esthetic and Restor Dent 2003;15(5):297-303; discussion 304.

27. Aliping-McKenzie M, Linden RW, Nicholson JW. The effect of Coca-Cola and fruit juices on the surface hardness of glass-ionomers and 'compomers'. J Oral Rehabil 2004 Nov; 31(11):1046-1052.

28. Ertas E, Guler AU, Yucel AC, Koprulu H, Guler E. Color stability of resin composites after immersion in different drinks. Dent Materials J 2006 Jun;25(2):371-376.

29. Pires-de-Souza Fde C, Garcia Lda F, Roselino Lde M, Naves LZ. Color stability of silorane-based composites submitted to accelerated artificial ageing — an in situ study. J Dent 2011;39 (Suppl 1):e18-24.

30. Palin WM, Fleming GJ, Burke FJ, Marquis PM, Randall RC. The influence of short and medium-term water immersion on the hydrolytic stability of novel low-shrink dental composites. Dent Materials 2005 Sep;21(9):852-863.

31. Weinmann W, Thalacker C, Guggenberger R. Siloranes in dental composites. Dent Mater 2005 Jan;21(1):68-74.

32. Reis AF, Giannini M, Lovadino JR, Ambrosano GM. Effects of various finishing systems on the surface roughness and staining susceptibility of packable composite resins. Dent Mater 2003 Jan;19(1):12-18.

33. Barutcugil C, Yildiz M. Intrinsic and extrinsic discoloration of dimethacrylate and silorane based composites. J Dent 2012 July;40(Suppl 1):e57-63.

34. Tjan AH, Chan CA. The polishability of posterior composites. J Prosthet Dentist 1989 Feb;61(2):138-146.

35. Yap AU, Lye KW, Sau CW. Surface characteristics of toothcolored restoratives polished utilizing different polishing systems. Operat Dentist 1997 Nov-Dec;22(6):260-265.

36. Venturini D, Cenci MS, Demarco FF, Camacho GB, Powers JM. Effect of polishing techniques and time on surface roughness, hardness and microleakage of resin composite restorations. Operat Dentist 2006 Jan-Feb;31(1):11-17.

37. Turkun LS, Turkun M. The effect of one-step polishing system on the surface roughness of three esthetic resin composite materials. Oper Dent 2004 Mar-Apr;29(2):203-211.

38. Antonson SA, Yazici AR, Kilinc E, Antonson DE, Hardigan PC. Comparison of different finishing/polishing systems on surface roughness and gloss of resin composites. J Dent 2011;39(Suppl 1): e9-17.

39. Kitchens M, Owens BM. Effect of carbonated beverages, coffee, sports and high energy drinks, and bottled water on the in vitro erosion characteristics of dental enamel. J Clin Ped Dentist 2007; Spring 31(3):153-159.

40. Da Silva MA, Fardin AB, de Vasconcellos RC, Santos Lde M, Tonholo J, da Silva JG Jr, dos Reis JI. Analysis of roughness and surface hardness of a dental composite using atomic force microscopy and microhardness testing. Microscopy and Microanalysis 2011 Jun;17(3):446-451.

41. Schmitt VL, Puppin-Rontani RM, Naufel FS, Nahsan FP, Alexandre Coelho Sinhoreti M, Baseggio W. Effect of the polishing procedures on color stability and surface roughness of composite resins. ISRN Dent 2011;617672. Epub 2011 Jul 11.

42. Soderholm KJ. Degradation of glass filler in experimental composites. J Dent Res 1981 Nov;(11):1867-1875.

43. Hansen EK. After-polymerization of visible light activated resins: surface hardness vs light source. Scandinavian J Dent Res 1983 Oct;91(5):406-410.

44. Bayindir YZ, Yildiz M. Surface hardness properties of resinmodified glass ionomer cements and polyacid-modified composite resins. J Contemp Dent Pract 2004 Nov 15;5(4):42-49.

45. Canay S, Cehreli MC. The effect of current bleaching agents on the color of light-polymerized composites in vitro. J Prosthet Dent 2003 May;89(5):474-478.

46. Honorio HM, Rios D, Francisconi LF, Magalhaes AC, Machado MA, Buzalaf MA. Effect of prolonged erosive $\mathrm{pH}$ cycling on different restorative materials. J Oral Rehabil 2008 Dec;35(12): 947-953.

47. Fontes ST, Fernandez MR, de Moura CM, Meireles SS. Color stability of a nanofill composite: effect of different immersion media. J Appl Oral Sci 2009 Sep-Oct;17(5):388-391.

48. Hamouda IM. Effects of various beverages on hardness, roughness, and solubility of esthetic restorative materials. J Esthetic Restorat Dentist 2011 Oct;23(5):315-322.

49. Calais JG, Söderholm KJ. Influence of filler type and water exposure on flexural strength of experimental composite resins. J Dent Res 1988 May;67(5):836-840. 